\begin{tabular}{|c|l|}
\hline Title & $\begin{array}{l}\text { Practical synthesis of pinacol borane for one pot synthesis of unsymmetrical biaryls via aromatic C-H borylation-cross } \\
\text { coupling sequence }\end{array}$ \\
\hline Author(s) & Kikuchi, Takao; Nobuta, Y usuke; U meda, Junko; Y amamoto, Y asunori; Ishiy ama, Tatsuo; Miyaura, Norio \\
\hline Citation & $\begin{array}{l}\text { Tetrahedron, 64(22), 4967-4971 } \\
\text { https:/doi.org/10.1016/.tet.2008.03.102 }\end{array}$ \\
\hline Issue Date & 2008-05-26 \\
\hline Doc URL & http://hdl.handle.net/2115/56361 \\
\hline Type & article (author version) \\
\hline File Information & (48) A r-Ar (B-B + H-Ar) (Full).pdf \\
\hline
\end{tabular}

Instructions for use 


\title{
Practical Synthesis of Pinacolborane for One-pot Synthesis of Unsymmetrical Biaryls via Aromatic C-H Borylation-Cross-Coupling Sequence
}

Takao Kikuchi, Yusuke Nobuta, Junko Umeda, Yasunori Yamamoto, ${ }^{*}$ Tatsuo Ishiyama, ${ }^{*}$ Norio Miyaura*

Division of Chemical Process Engineering, Graduate School of Engineering, Hokkaido University, Sapporo 060-8628, Japan

\begin{abstract}
A method for practical preparation of pinacolborane from borane-diethylaniline and pinacol was newly developed. Aromatic C-H borylation of arenes with pinacolborane or bis(pinacolato)diboron catalyzed by $1 / 2[\operatorname{Ir}(\mathrm{OMe})(\mathrm{COD})]_{2}-(4,4$ '-di-tert-butyl-2,2'bipyridine) at $25{ }^{\circ} \mathrm{C}$ in hexane to give arylboronic esters was directly followed by cross-coupling with aromatic bromides at $60{ }^{\circ} \mathrm{C}$ in the presence of $\mathrm{PdCl}_{2}$ (dppf) $(3.0$ mol\%) and $\mathrm{K}_{3} \mathrm{PO}_{4}$ in DMF. This one-pot, two-step procedures provided a variety of unsymmetrical biaryls in high yields.

Keywords: pinacolborane; biaryls; boron; C-H activation; cross-coupling
\end{abstract}

\section{Introduction}

Unsymmetrical biaryls are an important class of compounds due to the frequent occurrence of these fragments in natural products, pharmaceuticals, agrochemicals, and functional organic materials. ${ }^{1}$ Transition metal-catalyzed cross-coupling of arylmetal compounds with aryl halides or triflates has been proved to be a general method applicable for preparation of such unsymmetrical biaryls. ${ }^{\text {d, }, 1 \mathrm{f}}$ Among them, much attention has been focused on the use of arylboronic acids or esters in laboratories and industries since they are nontoxic, thermally stable, and inert to water and oxygen. A traditional method for preparations of such arylboron compounds is alkylation of $\mathrm{B}(\mathrm{OR})_{3}$ with aromatic lithium or magnesium reagents. ${ }^{2}$ Alternative synthesis based on palladium-catalyzed cross-couplings of aryl halides and triflates with bis(pinacolato)diboron $\left(\mathrm{B}_{2} \mathrm{pin}_{2} \text {, pin }=\mathrm{Me}_{4} \mathrm{C}_{2} \mathrm{O}_{2}\right)^{3}$ or pinacolborane (HBpin) ${ }^{4}$ are milder variants displayed high functional group compatibility. Another economical and environmentally benign process is transition metal-catalyzed direct $\mathrm{C}-\mathrm{H}$ borylation of arenes developed by Hartwig ${ }^{5}$ and Smith $^{6}$. Among the catalysts developed to date, ${ }^{7}$ a 
combination of $[\operatorname{Ir}(\mathrm{OMe})(\mathrm{COD})]_{2}$ and 4,4'-di-tert-butyl-2,2'-bipyridine (dtbpy) was recognized to be the best catalyst which allowed stoichiometric borylation of arenes with $\mathrm{B}_{2}$ pin $_{2}$ or HBpin at room temperature. ${ }^{8}$ Pinacolborane necessary for these coupling reactions is available from pinacol and borane-THF or borane-methyl sulfide complex (BMS). ${ }^{9}$ However, the protocol using $\mathrm{BH}_{3} \cdot \mathrm{THF}$ and $\mathrm{BH}_{3} \cdot \mathrm{SMe}_{2}$ is not suited for large-scale preparation due to certain inconveniences, e.g., the low concentration of and instability of $\mathrm{BH}_{3}$.THF and high volatility, flammability and unpleasant odor of dimethyl sulfide from $\mathrm{BH}_{3} \cdot \mathrm{SMe}_{2}$. Because of growing importance of pinacolborane for the syntheses of boron compounds, a practical method for its large-scale preparation can be desirable. Here, we disclose a method for synthesizing pinacolborane from amine-borane complexes and its use for a sequence of the iridium-catalyzed aromatic $\mathrm{C}-\mathrm{H}$ borylation and the palladium-catalyzed cross-coupling with aryl bromides to create convenient, one-pot procedure for the synthesis of unsymmetrical biaryls.

\section{Results and discussion}

\section{2-1. Synthesis of pinacolborane}

The first synthesis of HBpin (1) in 63\% yield reported by Knochel involves reaction between $\mathrm{BH}_{3} \cdot \mathrm{SMe}_{2}$ (BMS) and pinacol (Eq. 1). ${ }^{9}$ We adopted the use of amine-borane complexes as a borane source due to their advantage in large-scale preparation because of high thermal stability, low vapor pressure, inflammability and unpleasant odor. ${ }^{10}$ Borane-amine complexes are accessible by a reaction between metal borohydride and $\mathrm{HNR}_{3} \mathrm{Cl}^{11}$ or by treatment of $\mathrm{BH}_{3} \cdot \mathrm{THF}$ or $\mathrm{BH}_{3} \cdot \mathrm{SMe}_{2}$ with amines. ${ }^{10}$ To investigate their reaction with pinacol to give HBpin, representative borane-amine complexes (2) were synthesized by treatment of $\mathrm{BH}_{3} \cdot \mathrm{SMe}$ with amines in THF. ${ }^{10}$ Evaporation of the solvent and dimethyl sulfide in vacuo gave pure 2 in quantitative yields for $\mathrm{NH}_{3}$, 2,6-diisopropylaniline, N,N-dimethylaniline, N,N-diethylaniline, $\mathrm{N}$-ethyl-N-isopropylaniline and diisopropylaniline (Eq 2). Sodium borohydride is an economical borane source that has been utilized for the preparation of $\mathrm{BH}_{3}$-THF or other borane-base adducts by treatment with $\mathrm{BF}_{3} \cdot \mathrm{OEt}_{2} .{ }^{12,13}$ Thus, we utilized this protocol for preparation of $\mathrm{BH}_{3} \cdot \mathrm{N}(\mathrm{Ph}) \mathrm{Et}_{2}$ (2d) (Eq. 3). The reaction took place smoothly in the presence of $\mathrm{N}, \mathrm{N}$-diethylaniline in THF. Filtration of $\mathrm{NaBF}_{4}$ through a Celite pad and evaporation of THF in vacuo afford $\mathbf{2 d}$ in $89 \%$ yield. The preparation of 2d suffered from some contamination of fluoroborane species. This byproduct was completely eliminated when $\mathrm{NaBH}_{4}$ was used in slightly excess (1.07 eq) of the required stoichiometry for $\mathrm{BF}_{4} \cdot \mathrm{OEt}_{2}$. By this method, $0.42 \mathrm{~mol}$ of pure $\mathbf{2 d}$ was obtained from $0.5 \mathrm{~mol}$ of $\mathrm{NaBH}_{4}$. 
Reaction of pinacol with these borane-amines complexes in tetraglyme yielded HBpin (1) and $\mathrm{B}_{2} \operatorname{pin}_{3}(3)^{14}$ with various molar ratios (Table 1). The conversions of borane-amine complexes $(\mathbf{2}, \delta-21--6 \mathrm{ppm})$ and ratios of $\mathbf{1}(\delta 28 \mathrm{ppm})$ and $\mathbf{3}(\delta 20-22$ $\mathrm{ppm})$ were determined by ${ }^{11} \mathrm{~B}$ NMR. The reaction was very slow for stable, small amine complexes such as $\mathrm{NH}_{3}$ and dimethylaniline complex (entries 1 and 3) and fast for much sterically hindered 2,6-diisopropylaniline and diethylaniline complex (entries 2 and 4). Further increase in steric hindrance by $\mathrm{N}$-substituents resulted in no reaction (entries 6 and 7). Selectivities giving HBpin toward 3 were parallel to these reaction rates. Thus, $100 \%$ selectivity was achieved by diethylamine complex which exhibited the fastest reaction rate among six complexes examined (entry 4). However, isolation of HBpin suffered from low yields (ca. 50\%) because of formation of non volatile 3 during distillation in vacuo. It was difficult to prevent this equilibration when stoichiometric amount of $2 \mathbf{d}$ and pinacol were used, ${ }^{15}$ but the yield was improved to $75 \%$ in the presence of $50 \%$ excess of $\mathrm{BH}_{3} \cdot \mathrm{N}(\mathrm{Ph}) \mathrm{Et}_{2}$ toward pinacol (entry 5).

\section{2-2. One-pot synthesis of biaryls}

Aromatic C-H borylation with HBpin (1) or $\mathrm{B}_{2} \mathrm{pin}_{2}$ takes place at room temperature in the presence of an iridium(I)-dtbpy catalyst. The preparation of 1.1 equivalents of arylboronate (5) was directly followed by cross-coupling with bromoarenes for one-pot synthesis of biaryls (6) (Scheme 1).

Previous studies on the aromatic C-H borylation of aromatic compounds reported by Smith's group ${ }^{6}$ and by us ${ }^{7,8}$ are summarized in Scheme 2. Functional group tolerance of the borylation is very high. The reaction selectively occurs at the $\mathrm{C}-\mathrm{H}$ bond for substrates possessing $\mathrm{Cl}, \mathrm{Br}, \mathrm{I}, \mathrm{CF}_{3}, \mathrm{OMe}, \mathrm{CO}_{2} \mathrm{Me}$, and $\mathrm{CN}$ groups. The reaction occurs only at the aromatic $\mathrm{C}-\mathrm{H}$ bonds even when the substrate has weaker benzylic $\mathrm{C}-\mathrm{H}$ bonds. ${ }^{16,17}$ The regiochemistry of the borylation of arenes is primarily controlled by the steric effects of substituents. The reaction occurs at $\mathrm{C}-\mathrm{H}$ bonds located meta or para to a substituent in preference to those located ortho. Thus, 1,2-disubstituted arenes bearing identical substituents yield arylboronates as single isomers. The borylation of 1,3-disubstituted arenes proceeds at the common meta position; therefore, isomerically pure products are obtained even for two distinct substituents on the arenes. ${ }^{7}$ In the case of five-membered heteroarenes such as furans, thiophenes and pyrroles, the electronegative heteroatom causes the $\mathrm{C}-\mathrm{H}$ bonds at the $\alpha$-positions to be active so that the borylation occurs at the $\alpha$-positions. ${ }^{18}$ Thus, the regioselective monoborylation of benzo-fused substrates can be possible. In this study, we employed such arenes that produce single arylboronic ester (5). 
In one-pot, two-step reactions where each step is catalyzed by different metal complexes, a catalyst used at first step often inhibits second step. Thus, our initial efforts were focused on finding effective reaction conditions for the second cross-coupling step (Table 2). Pinacol 3,5-dichlorophenylborate (ca. $1.1 \mathrm{mmol}$ ) was prepared in situ by the C-H borylation of 1,3-dichlorobenzene $(1.36 \mathrm{mmol})$ with pin $_{2} \mathrm{~B}_{2}$ $2(0.65 \mathrm{mmol})$ in the presence of the $1 / 2[\operatorname{Ir}(\mathrm{OMe})(\mathrm{COD})]_{2}$-dtbpy catalyst $(0.020 \mathrm{mmol})$ in hexane $(2 \mathrm{~mL})$ at $25^{\circ} \mathrm{C}$ for $4 \mathrm{~h}$. This solution was directly allowed to react with bromobenzene $(1.0 \mathrm{mmol})$ at $60{ }^{\circ} \mathrm{C}$ for $2 \mathrm{~h}$ by using a variety of palladium catalysts $(0.03 \mathrm{mmol})$, bases $(3 \mathrm{mmol})$, and solvents $(4 \mathrm{~mL})$. Fortunately, it was found that a combination of $\mathrm{PdCl}_{2}(\mathrm{dppf}), \mathrm{K}_{3} \mathrm{PO}_{4} \bullet \mathrm{nH}_{2} \mathrm{O}$, and $\mathrm{DMF}$ works well to form the desired 3,5-dichlorobiphenyl in 96\% yield (entry 1). Use of $\mathrm{PdCl}_{2}\left(\mathrm{PPh}_{3}\right)_{2}$ (entry 2) or $\mathrm{Pd}(\mathrm{dba})_{2}$ (entry 3 ) resulted in low yield due to formation of inactive palladium-black. As for bases, $\mathrm{K}_{3} \mathrm{PO}_{4}$ in DMF gave the best results among four bases employed (entries 1 and 4-6). The reactions were faster in polar DMF (Entry 7) than in less-polar dioxane and hexane (entries 7 and 8 ). The $\mathrm{C}$-H borylation of 1,3-dichlorobenzene $(1.30 \mathrm{mmol})$ with HBpin $(1.43 \mathrm{mmol})$ at $25{ }^{\circ} \mathrm{C}$ for $8 \mathrm{~h}$ yielded pinacol 3,5-dichlorophenylboronate (ca. 1.1 mmol). Its cross-coupling with bromobenzene $(1.0 \mathrm{mmol})$ with $\mathrm{PdCl}_{2}(\mathrm{dppf})$, $\mathrm{K}_{3} \mathrm{PO}_{4} \bullet \mathrm{nH}_{2} \mathrm{O}$ in DMF was also effective for synthesis of 3,5-dichlorobiphenyl in $93 \%$ yield (entries 9).

Representative results of one-pot synthesis of unsymmetrical biaryls (6) via the sequential reactions involving the aromatic $\mathrm{C}-\mathrm{H}$ borylation of arenes with $\mathrm{B}_{2}$ pin $_{2}$ (Method A) or that by HBpin (1) (Method B) and the cross-coupling with bromoarenes under the conditions optimized in Table 2 are summarized in Table 3 . The method provides a convenient and efficient route for preparing a variety of $\mathbf{6}$. Representative bromoarenes possessing an electron-withdrawing group, donating group, and an ortho-substituent afforded 6 in high yields (entries 1-7), while electron-rich (entry 3) or sterically hindered bromoarene (entry 4) required longer reaction times to complete the cross-coupling. The $\mathrm{C}-\mathrm{H}$ borylation of 1,3-disubstituted arenes having two distinct substituents (entries 5 and 6) and 1,2-disubstituted arenes bearing identical substituents (entry 7) generated isomerically pure arylboronates and biaryls. Although $\alpha$-hetroarylboronic acids such as 2-pyridineboronic acid and 2-pyrroleboronic acid are highly susceptible to hydrolytic protodeboration, the corresponding pinacol esters are much sable for such B-C bond cleavage in the presence of a base. Thus, 2-indoleboronate generated from indole smoothly coupled with 2-bromothiophene (entry 8). There were no significant differences in the yields and reaction rates between method $\mathrm{A}$ and $\mathrm{B}$, but high stability of $\mathrm{B}_{2} \mathrm{pin}_{2}$ to air and water can be convenient for 
handling and economical HBpin can be much suited for large-scale preparation of arylboronates and biaryls.

\section{Experimental}

\subsection{Synthesis of borane-amine complexes (2)}

Borane/amine complexes (2) were synthesized by the methods of Vaultier and Brown. ${ }^{10}$ The synthesis of $\mathbf{2 d}$ from $\mathrm{NaBH}_{4}, \mathrm{BF}_{3} \cdot \mathrm{OEt}_{2}$ and $\mathrm{PhNEt}_{2}$ is followed.

A 500-mL flask charged with $\mathrm{NaBH}_{4}(0.4 \mathrm{~mol})$ and $\mathrm{PhNEt}_{2}(0.5 \mathrm{~mol})$ in THF (100 $\mathrm{mL})$ was dropwise added $\mathrm{BF}_{3} \cdot \mathrm{OEt}_{2}(0.5 \mathrm{~mol})$ at $-78{ }^{\circ} \mathrm{C}$. The mixture was allowed slowly warm to room temperature and stirred for 1-4 h. The complete disappearance of B-F species was checked by ${ }^{11} \mathrm{~B}$ NMR. The mixture was diluted with pentane $(100 \mathrm{~mL})$ to precipitate $\mathrm{NaBF}_{4}$. Filtration of solid residue through a Celite pad was followed by evaporation of solvent and other volatiles. Further evaporation of trace of volatiles in high vacuo $\left(10^{-2} \mathrm{mmHg}\right)$ for $16 \mathrm{~h}$ gave $72.5 \mathrm{~g}(89 \%)$ of 2 d. ${ }^{1} \mathrm{H}$ NMR (400 $\left.\mathrm{MHz}, \mathrm{CDCl}_{3}\right)$ $\delta 1.06$ (t, $J=7.16 \mathrm{~Hz}, 6 \mathrm{H}), 1.84$ (q, $\left.J=90.3 \mathrm{~Hz}, 3 \mathrm{H}, \mathrm{BH}_{3}\right), 3.29-3.40$ (m, 4H), 7.27 (t, $J=7.34 \mathrm{~Hz}, 1 \mathrm{H}), 7.38$ (t, $J=7.94 \mathrm{~Hz}, 2 \mathrm{H}), 7.65$ (d, $J=8.48 \mathrm{~Hz}, 2 \mathrm{H}) ;{ }^{11} \mathrm{~B}$ NMR (128 MHz, $\left.\mathrm{CDCl}_{3}\right) \delta-12.0$.

\subsection{Synthesis of pinacolborane}

A $100 \mathrm{~mL}-f l a s k$, assembled a Claisen-head distillation apparatus, was charged with $\mathrm{BH}_{3} \cdot \mathrm{N}(\mathrm{Ph}) \mathrm{Et}_{2}(\mathbf{2 d}, 75 \mathrm{mmol})$ and tetraglyme $(20 \mathrm{~mL})$. A solution of pinacol $(50 \mathrm{mmol})$ in tetraglyme (5M solution, $10 \mathrm{~mL}$ ) was dropwise added over 30 min to the flask cooled by a water bath $\left(25{ }^{\circ} \mathrm{C}\right)$. The mixture was stirred for $30 \mathrm{~min}$ at room temperature. Distillation in vacuo gave pinacolborane $(4.8 \mathrm{~g}, 75 \%)$. Bp $36{ }^{\circ} \mathrm{C} / 42 \mathrm{mmHg} .{ }^{1} \mathrm{H}$ NMR $\left(400 \mathrm{MHz}, \mathrm{CDCl}_{3}\right) \delta 1.27(\mathrm{~s}, 12 \mathrm{H}), 4.10$ (q, $\left.J=168 \mathrm{~Hz}, 1 \mathrm{H}\right) ;{ }^{11} \mathrm{~B}$ NMR $(128 \mathrm{MHz}$, $\left.\mathrm{CDCl}_{3}\right) \delta 28.1$.

\subsection{Procedure for one-pot biaryl cross-coupling using $B_{2}$ pin $_{2}$ (Method A)}

A 25-mL flask assembled a magnetic stirring bar, a septum inlet, and a condenser was charged with $[\operatorname{Ir}(\mathrm{OMe})(\mathrm{COD})]_{2}{ }^{19}$ (0.01 mmol), 4,4'-di-tert-butyl-2,2'-bipyridine (dtbpy, $0.02 \mathrm{mmol}$ ), and bis(pinacolato)diboron $\left(\mathrm{B}_{2} \mathrm{pin}_{2}, 0.65 \mathrm{mmol}\right.$ ) and then flushed with nitrogen. Hexane $(2 \mathrm{~mL})$ and 1,3-dichlorobenzene $(1.36 \mathrm{mmol})$ were added, and the mixture was then stirred at $25{ }^{\circ} \mathrm{C}$ for $4 \mathrm{~h}$ to give pinacol 3,5-dichlorophenylboronate (ca. $1.1 \mathrm{mmol})$. To this solution were added $\mathrm{PdCl}_{2}(\mathrm{dppf})(0.030 \mathrm{mmol}), \mathrm{K}_{3} \mathrm{PO}_{4} \cdot \mathrm{nH}_{2} \mathrm{O}(3$ 
mmol), and DMF ( $4 \mathrm{~mL})$, and the mixture was stirred at $60^{\circ} \mathrm{C}$ for $2 \mathrm{~h}$. The formation of methyl 4-(3,5-dichlorophenyl)benzoate (2b) in 96\% yield was analyzed by GC and GC mass spectroscopy. The product was extracted with benzene, washed with brine, and dried over $\mathrm{MgSO}_{4}$. Chromatography over silica gel (hexane/AcOEt) gave analytically pure $\mathbf{2 b}$.

3.4. Procedure for one-pot biaryl cross-coupling using HBpin (Method B)

A 25-mL flask assembled a magnetic stirring bar, a septum inlet, and a condenser was charged with $[\operatorname{Ir}(\mathrm{OMe})(\mathrm{COD})]_{2}{ }^{19} \quad(0.02 \quad \mathrm{mmol}) \quad$ and 4,4'-di-tert-butyl-2,2'-bipyridine (dtbpy, $0.04 \mathrm{mmol}$ ) and then flushed with nitrogen. Hexane $(2 \mathrm{~mL})$, pinacolborane (HBpin, $1.43 \mathrm{mmol})$, and 1,3-dichlorobenzene (1.3 mmol) were then added, and the mixture was stirred at $25^{\circ} \mathrm{C}$ for $8 \mathrm{~h}$ to give pinacol 3,5-dichlorophenylboronate (ca. $1.1 \mathrm{mmol}$ ). The solution thus obtained was directly subjected to cross-coupling under conditions same as the above procedures shown in the section 3.3 . 


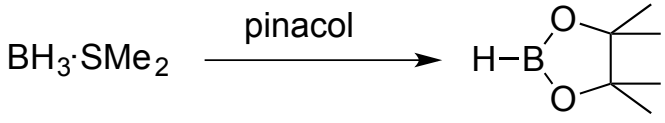

$$
\begin{aligned}
& 1 \text { (HBpin) }
\end{aligned}
$$

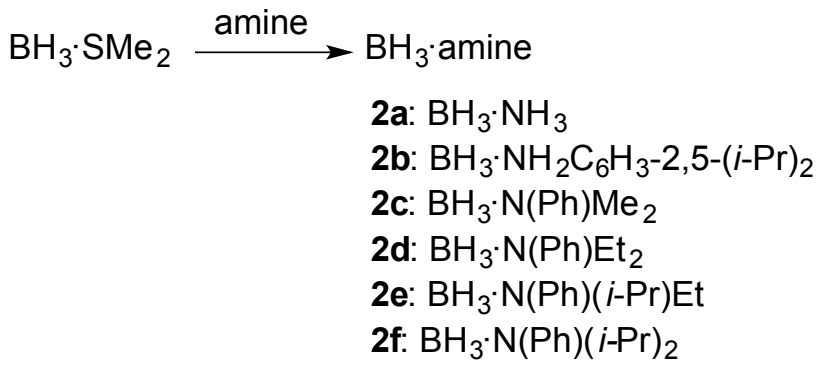<smiles>CC1(C)OB(OC(C)(C)C(C)(OB2OC(C)(C)C(C)(C)O2)OC2(C)OB(B3OC(C)(C)C(C)(C)O3)OC2(C)C)OC1(C)C</smiles>

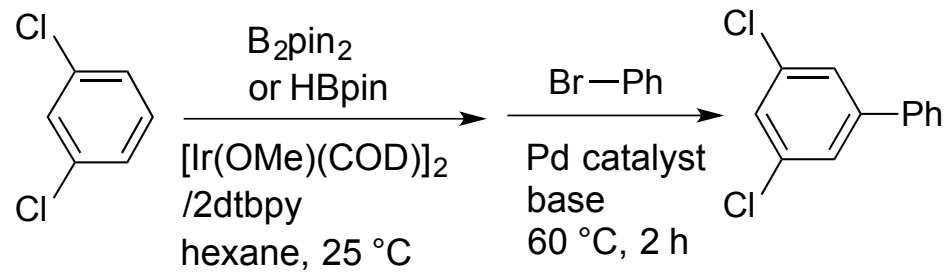




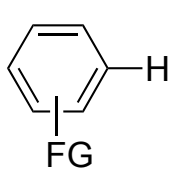

4 $\underset{1 / 2[\operatorname{Ir}(\mathrm{OMe})(\mathrm{COD})]_{2} \text {-dtbpy }}{\stackrel{1 / 2 \mathrm{~B}_{2} \mathrm{pin}_{2} \text { or HBpin }}{\longrightarrow}}$ hexane, $25^{\circ} \mathrm{C}$

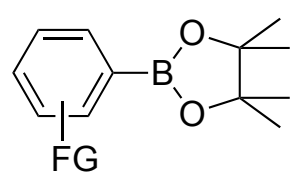

5
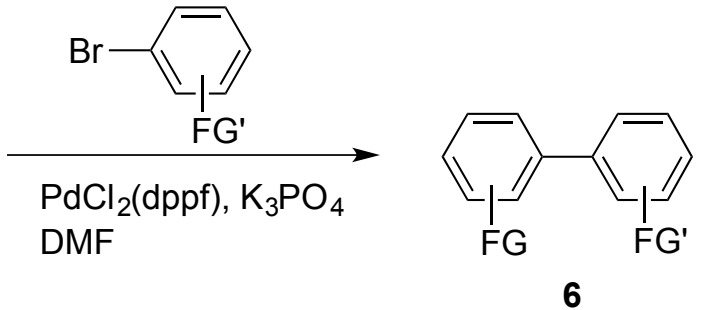

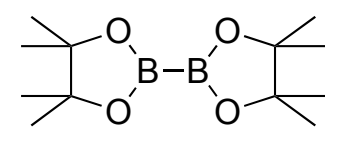

$\mathrm{B}_{2}$ pin $_{2}$<smiles>CC(C)(C)c1ccnc(-c2cc(C(C)(C)C)ccn2)c1</smiles>

Scheme 1. One-pot synthesis of biaryls via aromatic C-H borylation-cross-coupling sequnce. 


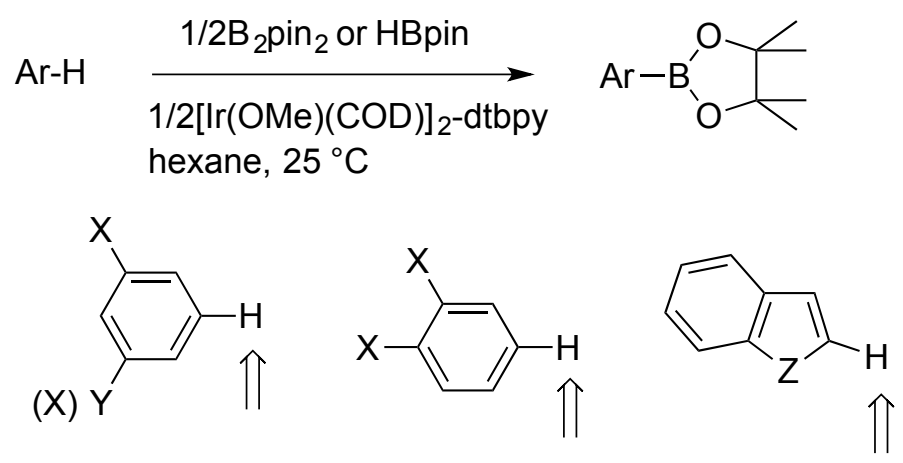

Scheme 2. Orientations of aromatic C-H borylation 
Table 1. Synthesis of pinacolborane ${ }^{a}$

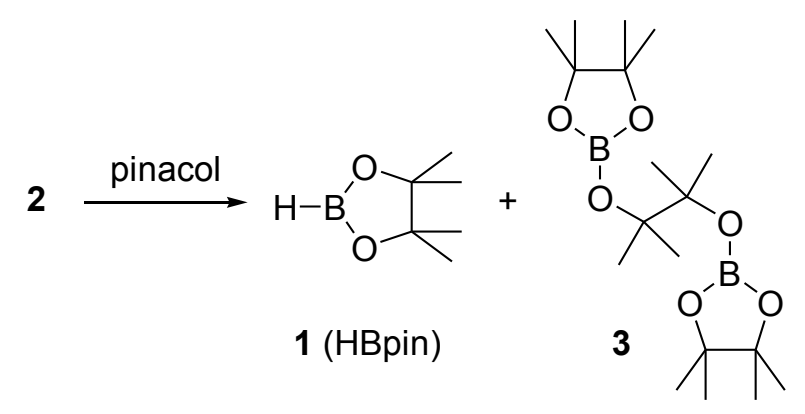

\begin{tabular}{|c|c|c|c|c|}
\hline entry & 2 (amine $=)$ & conversion $/ \%{ }^{b}$ & $1 / 3$ & $\begin{array}{l}\text { isolated } \\
\text { yield } / \%\end{array}$ \\
\hline 1 & $\mathrm{NH}_{3}(\mathbf{2 a})$ & 12 & $42: 58$ & \\
\hline 2 & 2,6- $(i-\mathrm{Pr})_{2} \mathrm{C}_{6} \mathrm{H}_{3} \mathrm{NH}_{2}(\mathbf{2 b})$ & 82 & $85: 15$ & \\
\hline 3 & $\mathrm{PhNMe}_{2}(\mathbf{2 c})$ & 43 & $60: 40$ & \\
\hline 4 & $\mathrm{PhNEt}_{2}$ (2d) & 100 & 100: 0 & (50) \\
\hline 5 & $\mathrm{PhNEt}_{2}(\mathbf{2 d})^{c}$ & 100 & $100: 0$ & $(75)$ \\
\hline 6 & $\operatorname{PhN}(i-\operatorname{Pr}) \operatorname{Et}(\mathbf{2 e})$ & 0 & & \\
\hline 7 & $\operatorname{PhN}(i-\operatorname{Pr})_{2}(\mathbf{2 f})$ & 0 & & \\
\hline
\end{tabular}

${ }^{a}$ A mixture of amine-borane complex $(50 \mathrm{mmol})$ and pinacol $(50 \mathrm{mmol})$ in tetraglyme $(5 \mathrm{ml})$ was stirred for $1 \mathrm{~h}$ at $20{ }^{\circ} \mathrm{C}$.

${ }^{b}$ Conversions and ratios determined by ${ }^{11} \mathrm{~B}$ NMR.

${ }^{c} 1.5$ equivalents of $\mathbf{2} \mathbf{d}$ was used. 
Table 2. Reaction conditions for one-pot synthesis of biaryls ${ }^{a}$

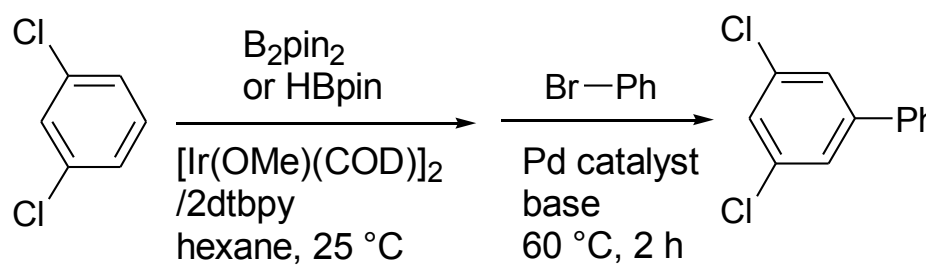

\begin{tabular}{|c|c|c|c|c|c|}
\hline entry & $\begin{array}{l}\mathrm{B}_{2} \mathrm{pin}_{2} \\
\text { or HBpi }\end{array}$ & Pd catalyst & base & solvent & yield $/ \%^{b}$ \\
\hline 1 & $\mathrm{~B}_{2} \mathrm{pin}_{2}$ & $\mathrm{PdCl}_{2}(\mathrm{dppf})$ & $\mathrm{K}_{3} \mathrm{PO}_{4}$ & DMF & 96 \\
\hline 2 & $\mathrm{~B}_{2} \mathrm{pin}_{2}$ & $\mathrm{PdCl}_{2}\left(\mathrm{PPh}_{3}\right)_{2}$ & $\mathrm{~K}_{3} \mathrm{PO}_{4}$ & $\mathrm{DMF}$ & 55 \\
\hline 3 & $\mathrm{~B}_{2} \mathrm{pin}_{2}$ & $\operatorname{Pd}(\mathrm{dba})_{2}$ & $\mathrm{~K}_{3} \mathrm{PO}_{4}$ & $\mathrm{DMF}$ & 1 \\
\hline 4 & $\mathrm{~B}_{2} \mathrm{pin}_{2}$ & $\mathrm{PdCl}_{2}(\mathrm{dppf})$ & $\mathrm{Cs}_{2} \mathrm{CO}_{3}$ & DMF & 88 \\
\hline 5 & $\mathrm{~B}_{2} \mathrm{pin}_{2}$ & $\mathrm{PdCl}_{2}(\mathrm{dppf})$ & $\mathrm{K}_{2} \mathrm{CO}_{3}$ & DMF & 80 \\
\hline 6 & $\mathrm{~B}_{2} \mathrm{pin}_{2}$ & $\mathrm{PdCl}_{2}(\mathrm{dppf})$ & KOAc & $\mathrm{DMF}$ & 53 \\
\hline 7 & $\mathrm{~B}_{2} \mathrm{pin}_{2}$ & $\mathrm{PdCl}_{2}(\mathrm{dppf})$ & $\mathrm{K}_{3} \mathrm{PO}_{4}$ & dioxane & 84 \\
\hline 8 & $\mathrm{~B}_{2} \mathrm{pin}_{2}$ & $\mathrm{PdCl}_{2}(\mathrm{dppf})$ & $\mathrm{K}_{3} \mathrm{PO}_{4}$ & hexane & 9 \\
\hline 9 & HBpin & $\mathrm{PdCl}_{2}(\mathrm{dppf})$ & $\mathrm{K}_{3} \mathrm{PO}_{4}$ & DMF & 93 \\
\hline
\end{tabular}

${ }^{a} \mathrm{C}$-H borylation of 1,3-dichlorobenzene $(1.36 \mathrm{mmol})$ with $\mathrm{B}_{2} \operatorname{pin}_{2}(0.65 \mathrm{mmol})$ in hexane $(2 \mathrm{~mL})$ at $25{ }^{\circ} \mathrm{C}$ for $4 \mathrm{~h}$ in the presence of $1 / 2[\operatorname{Ir}(\mathrm{OMe})(\mathrm{COD})]_{2}$-dtbpy $(3.0$ $\mathrm{mol} \%, 0.020 \mathrm{mmol})$ was followed by cross-coupling with bromobenzene $(1.0 \mathrm{mmol})$ at $60{ }^{\circ} \mathrm{C}$ for $2 \mathrm{~h}$ by using Pd catalyst $(0.030 \mathrm{mmol})$, base $(3.0 \mathrm{mmol})$, and solvent $(4$ $\mathrm{mL})$.

${ }^{b} \mathrm{GC}$ yields based on bromobenzene. 
Table 3. One-pot Synthesis of biaryls via C-H borylation-cross-coupling sequence ${ }^{a}$

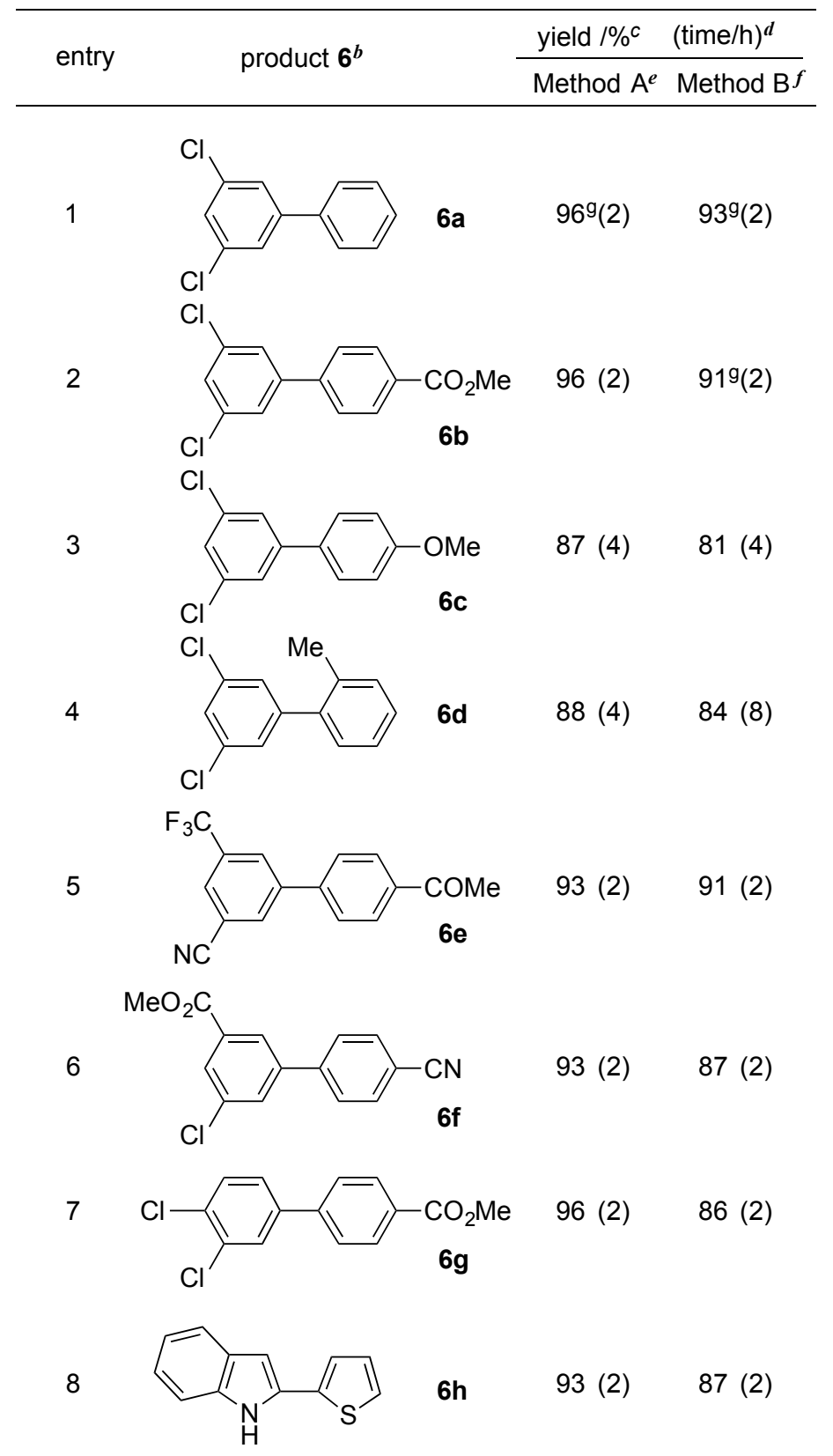

${ }^{a}$ The C-H borylation of arenes with $\mathrm{B}_{2}$ pin $_{2}$ (Method A) or HBpin (Method B) to give arylboronates (5, ca. 1.1 mmol) was followed by cross-coupling with aryl bromides $(1.0 \mathrm{mmol})$ at $60^{\circ} \mathrm{C}$ in the presence of $\mathrm{PdCl}_{2}(\mathrm{dppf})$ (0.03 mmol), $\mathrm{K}_{3} \mathrm{PO}_{4}(3 \mathrm{mmol})$ and DMF $(4 \mathrm{~mL})$..

${ }^{b}$ Left part of biaryls comes from arenes and right part from boromoarenes. $\quad{ }^{c}$ Isolated yields.

${ }^{d}$ Reaction times at the cross-coupling stage.

${ }^{e}$ The $\mathrm{C}-\mathrm{H}$ borylation of arene (1.30-1.43 mmol) with $\mathrm{B}_{2} \mathrm{pin}_{2}(0.63-0.69 \mathrm{mmol})$ was carried out for $0.5-8 \mathrm{~h}$ in the presence of $1 / 2[\operatorname{Ir}(\mathrm{OMe})(\mathrm{COD})]_{2}$-dtbpy $(3.0 \mathrm{~mol} \%, 0.020 \mathrm{mmol})$.

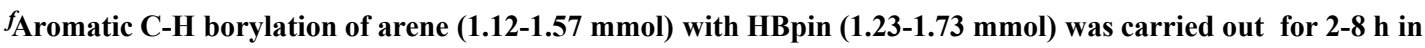
the presence of $1 / 2[\operatorname{Ir}(\mathrm{OMe})(\mathrm{COD})]_{2}$-dtbpy $(3.0 \mathrm{~mol} \%, 0.034-0.048 \mathrm{mmol})$.

${ }^{g} \mathbf{G C}$ yields. 
Graphical Abstract

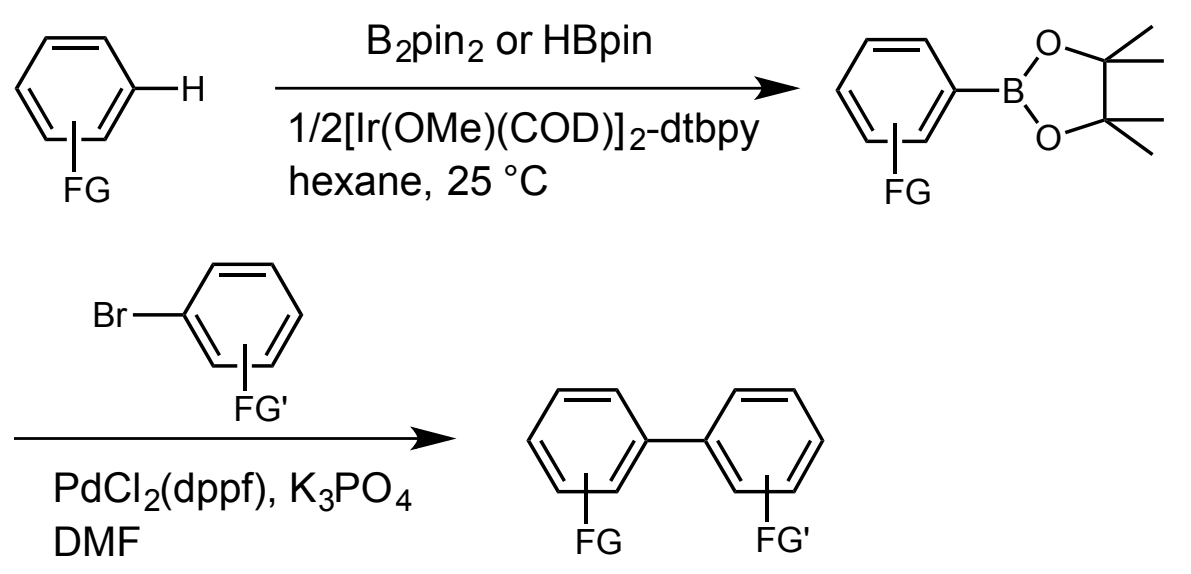

